\title{
A time-of-drug addition approach to target identification of antiviral compounds
}

\author{
Dirk Daelemans ${ }^{1}$, Rudi Pauwels ${ }^{1,2}$, Erik De Clercq ${ }^{1} \&$ Christophe Pannecouque ${ }^{1}$
}

${ }^{1}$ Rega Institute for Medical Research, Katholieke Universiteit Leuven, Leuven, Belgium. ${ }^{2}$ Present address: Biocartis SA, Parc Scientifique EPFL, Lausanne, Switzerland. Correspondence should be addressed to D.D. (dirk.daelemans@rega.kuleuven.be).

Published online 2 June 2011; doi:10.1038/nprot.2011.330

Insight into the mode of action of newly discovered antiviral agents is now almost a prerequisite for clinical development. This protocol describes a method that provides information on the target of inhibitors of the human immunodeficiency virus (HIV); it can also be adapted to other viruses. The results from this experiment are available within $2 \mathrm{~d}$. This time-based approach determines how long the addition of a compound can be postponed before losing its antiviral activity in cell culture. The target of an antiviral compound can be identified by comparing its relative position in the time scale to that of reference drugs. Therefore, it is more precise than, for example, in the case of HIV, a determination of pre- or postintegrational mode of action, and combines in one routine different assays for studying mechanisms of action.

\section{INTRODUCTION}

Shortly after the isolation of HIV, an intensive search for compounds that would inhibit infectivity and replication of this virus was initiated. A major breakthrough in this search was the establishment of a rapid and automated anti-HIV screening assay ${ }^{1,2}$. The active development of new anti-HIV compounds continues, and many lead compounds still emerge from initial antiviral screens. Knowing the target of action of these new drugs is not only of extreme importance for swift progress in the development of novel anti-HIV strategies but is also essentially a prerequisite for their clinical development.

\section{Methods for determining drug targets of action}

The in vitro tests most commonly used to determine the target of action of anti-HIV drugs are assays measuring the activity of the following viral enzymes: reverse transcriptase (RT) (polymerase and $\mathrm{RNaseH}$ activity $)^{3-7}$, integrase $\mathrm{e}^{8,9}$ and protease ${ }^{10}$. The advantage of these enzymatic assays in the test tube is that they are straightforward to perform, do not require any special safety infrastructure and produce clear interpretable results. However, if there are no previous indications of the presumed target of a new drug, it is difficult to know with which assay to start. In that case, viral resistance is selected against the inhibitor and the target of action is then needed to be determined by sequence analysis, which is time-consuming and cumbersome. Currently, many other test-tube assays have been described for measuring the distinct interactions (protein-protein, RNA-protein) that are essential for viral replication, and new assays are being developed ${ }^{11,12}$.

However, on the basis of test-tube studies of mechanisms of action, several compounds have been mistakenly ascribed to inhibit a certain target that, upon further study in cell culture, appeared to inhibit an off-site target. For example, suramin was first found to be a very potent inhibitor of the retroviral reverse transcription process in the test tube and to block the in vitro infectivity and cytopathic effect of $\mathrm{HIV}^{3,13}$. It was not only the first antiviral drug to be shown in vitro to block HIV infection but was also the first to be proven effective in suppressing HIV replication in HIVinfected patients ${ }^{14}$. Although suramin was originally pursued for its
anti-HIV potential because of its RT-inhibitory capacity, it has since become clear that, in cell culture, suramin primarily targets the viral adsorption step ${ }^{15}$ involving the viral envelope glycoprotein gp 120 (ref. 16). Another example is the Tat inhibitor CGP64222 (ref. 17), shown to target viral entry in cell culture ${ }^{18}$. Yet another example is L-chicoric acid and its derivatives, which counteract HIV-1 integrase activity in vitro but in cell culture block virus entry ${ }^{19,20}$. Therefore, tools to characterize the mechanism of action of virus inhibitors in cell culture are required to define their correct targets of action ${ }^{21}$.

There are several tests for studying the target of action of antiviral compounds in cell culture. For example, by comparing the activity of a compound on acutely ${ }^{1}$ versus persistently or latently infected cells ${ }^{22-24}$, it can be easily determined whether an inhibitor targets a pre- or a postintegrational step of the viral replication cycle $e^{25}$. A drug blocking the production of a new virus from persistently infected cells presumably targets a postintegrational event because in the persistent infection system all preintegrational steps, such as virus binding, reverse transcription and integration, are omitted. Alternatively, for several steps in the HIV replication cycle (e.g., virus binding ${ }^{26}$, integration ${ }^{21}$, transcription $^{27}$ and viral budding ${ }^{28}$ ), there exist specific tests in cells that can be performed to study the effect of a potential inhibitor of this target. For example, if one presumes that a newly discovered inhibitor interferes with virus binding, a virus-binding assay ${ }^{26}$ can be performed. However, none of these assays combine all these properties in just one test that covers a full replication cycle.

Overview of the time-of-addition method

In this protocol, we describe an approach routinely used in our lab that can be used to narrow down the mechanism/target of action of a newly discovered anti-HIV drug in cell culture by comparing its time of intervention with that of well-characterized inhibitors. This time-of-addition (TOA) approach determines how long the addition of a compound can be postponed before it loses its antiviral activity and was first used by Pauwels et al. ${ }^{29}$ to delineate the target of action of tetrahydro-imidazo[4,5,1-jk] 


\section{BOX 1 | STAGES OF HIV REPLICATION}

HIV replication involves several essential chronological steps (Fig. 3a) ${ }^{30}$. First, infectious virions bind to the cellular receptors on the surface of susceptible cells. Fusion of the viral envelope with the cellular membrane ensues, and the viral core penetrates into the cytoplasm. The single-stranded RNA genome of the virus is copied into a double-stranded linear DNA molecule by the viral enzyme reverse transcriptase. Next, the DNA is transported to the nucleus as a nucleic acid-protein complex (the preintegration complex) and is integrated into the host cell's genome by the action of a second viral enzyme, integrase. The covalently integrated form of viral DNA, which is defined as the provirus, serves as the template for transcription. The viral Tat protein stimulates transcription, and retroviral RNAs are synthesized, processed and then transported with the support of the viral protein Rev to the cytoplasm, where they are translated to produce the viral proteins. The proteins that form the viral core, encoded by the gag and pol genes, initially assemble into immature particles together with two copies of the full-length viral RNA. As these structures bud through the plasma membrane, they become enveloped by a lipid bilayer from the cell membrane that also harbors the viral Env glycoproteins in the form of trimers. Concomitantly with virus assembly and budding, the viral protease cleaves the Gag and Gag-Pol precursors to release the structural core proteins and pol enzymes in their final processed forms, resulting in a fully matured and infectious virus particle.

[1,4]-benzodiazepine-2-(1H)-one (TIBO) derivatives, later recognized as prototype of the NNRTIs (non-nucleoside RT inhibitors). Indeed, when an inhibitor that interferes with, for example, the viral RT enzyme, is present at the time when the reverse transcription process occurs within the viral replication cycle, it will be able to inhibit virus replication. In contrast, when this inhibitor is added once the reverse transcription is completed, the inhibitor will no longer be effective in blocking viral replication.

To replicate, HIV undergoes several major essential steps that occur in a well-established chronological order (see overview in Box 1 and ref. 30 for a review). A single round of HIV-1 replication takes $\sim 24 \mathrm{~h}$ (Fig. 1). Therefore, the standard protocol of a TOA experiment is based on the bulk infection of susceptible cells for $1 \mathrm{~h}$; this is followed by removing the unbound virus and subsequent dispensing of the infected cells in a 96-well tissue culture plate and adding test compounds at $0,1,2,3, \ldots, 24 \mathrm{~h}$ after virus infection. Further, the extent of virus replication is monitored at $31 \mathrm{~h}$ after infection. To synchronize the infection in all conditions, it is a prerequisite to wash out all unbound virus at $1 \mathrm{~h}$ after infection. The distinct steps of the procedure are detailed in Figure 2. Key to the success of the experiment and to obtaining a maximal viral output that can be reliably measured is the use of: a highly susceptible cell line, e.g., the human T-lymphotropic virus type I (HTLV-I)-transformed MT-4 cell line; a high multiplicity of infection (0.5-1); and an optimal harvest time. For HIV, the newly produced virus is harvested $31 \mathrm{~h}$ after infection (Fig. 1) to ensure that only one replication cycle has been completed.

As other viruses also undergo major processes of replication in a chronological order, this protocol can be adapted for the identification of the target of action of inhibitors of viruses other than HIV (e.g., coronaviruses) ${ }^{31,32}$. In principle, this protocol is applicable to any virus/inhibitor combination, although in the absence of known inhibitors of the replication of the virus under study, it would be more challenging to interpret the data. However, for most viruses at least a few inhibitors with an established mode of action are known.

The advantage of this method is that a single experiment will give an indication of the possible target of interaction of an inhibitor and provide the basis for further investigations. The major limitation, however, is the availability of well-characterized inhibitors for the virus of interest. In principle, the more wellcharacterized inhibitors that exist for a certain virus, the more precisely a TOA experiment can reveal the target of action of a new inhibitor. A second limiting factor is that the result obtained from compounds with limited selectivity is not easily interpretable. Indeed, the use of compound concentrations of 10- to 100 -fold their antiviral activity (half-maximum inhibitory concentration or $\mathrm{IC}_{50}$ ) are most favorable in this experiment, and compounds with limited selectivity will often be toxic at these concentrations.

\section{Experimental design}

Compound concentration. The antiviral activity $\left(\mathrm{IC}_{50}\right)$ and toxicity $\left(\mathrm{CC}_{50}\right)$ of a compound should be determined before a TOA experiment is performed. The concentration of compound used in the TOA experiment is 100 -fold its $\mathrm{IC}_{50}$, as established in an MT-4/MTT (3-(4,5-dimethylthiazol-2-yl)-2,5-diphenyltetrazolium bromide) assay ${ }^{1}$. It should be confirmed that the compound is not toxic to the cells at this concentration; if so, a lower concentration should be used, although we recommend not to use a concentration lower than tenfold its $\mathrm{IC}_{50}$, as this could result in

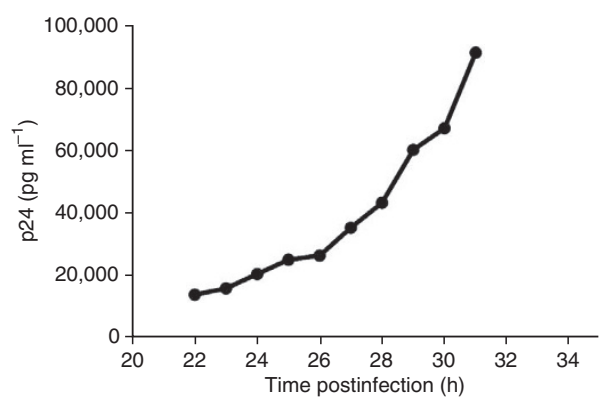

Figure 1 | Determination of the time necessary for one round of HIV-1 replication. Highly susceptible MT-4 cells were infected with HIV-1 at a high multiplicity of infection (0.5). Virus was incubated with cells for $1 \mathrm{~h}$ and unbound virus was subsequently removed by extensive and repeated washing to synchronize the replication. Next, infected cells were incubated for different time periods as indicated, and the produced (released) virus in the supernatant was quantified by monitoring the virus-associated Gag core p24 antigen. From $26 \mathrm{~h}$ after infection, an exponential increase in virus released in the supernatant of the infected cells was observed, demonstrating that one round of virus replication roughly encompasses $1 \mathrm{~d}$. 
an insufficient inhibition of viral replication. Moreover we recommend checking the solubility of the compound in aqueous medium at the intended concentration, as precipitation reduces the final concentration of the compound.

Virus replication capacity. Not any cell line can be used in this protocol. It is important to use a highly susceptible cell line in combination with a highly replicative virus to ensure that replication can be accurately measured $31 \mathrm{~h}$ after infection (in the case of HIV). A pretest should be carried out to ensure that sufficiently high virus production is measured after $31 \mathrm{~h}$ of infection (Fig. 1). For other viruses, the time required for one replication round should first be determined in order to assign a suitable detection window. In addition, the amount of inoculum required should be optimized to ensure that sufficient virus is released into the supernatant at the time of harvest.

Controls. If available, always include sufficient control/reference compounds that are well established in their target of interaction.

Detection of viral replication. The virus replication can be monitored in different ways. For HIV, usually the virus-associated p24 antigen in the supernatant of infected cells is quantified by ELISA (commercially available through different suppliers). Other methods such as virus-associated RT activity (assay kits are available through different suppliers) or quantitative RT-PCR ${ }^{33}$ can be used as alternatives.

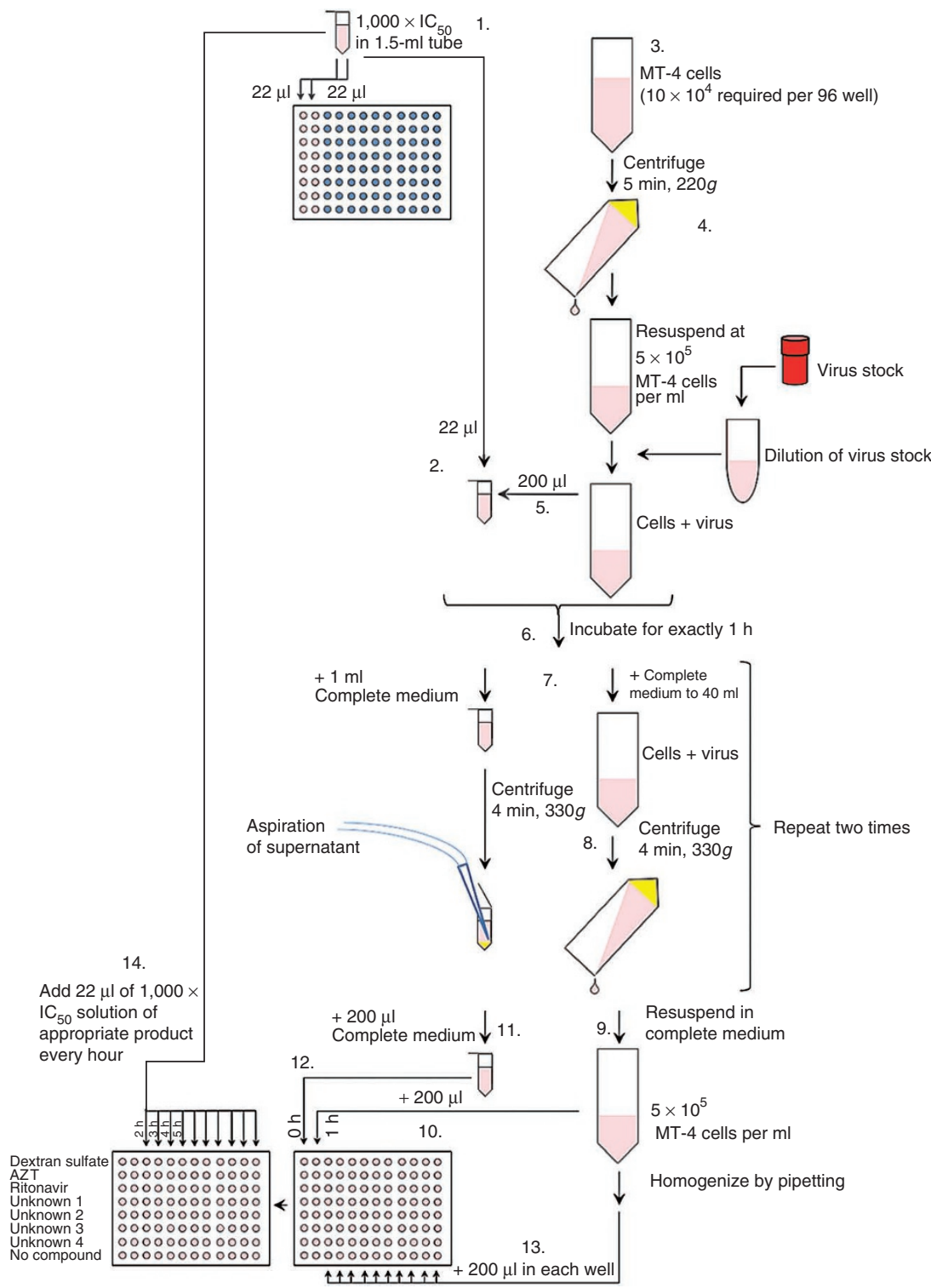

Figure 2 | Flow diagram outlining the time-of-addition procedure. Corresponding PROCEDURE step numbers are included.

\section{MATERIALS}

\section{REAGENTS}

- MT-4 cells. They can be obtained from the NIH AIDS Research and

Reference Reagent Program (cat. no. 120)

- Complete medium (see REAGENT SETUP)

- RPMI-1640 medium (1× with HEPES without glutamine; Invitrogen, cat. no. 42402016 )

- Heat-inactivated FCS (Invitrogen, cat. no. 10270-106)

- L-glutamine (Invitrogen, cat. no. 25030024)

- Gentamicin (50 mg ml-1, liquid; Invitrogen, cat. no. 15750045)

- Virus stock. It can be obtained from the NIH AIDS Research and Reference Reagent Program (cat. no. 398). Stocks should be prepared and titrated to determine the $50 \%$ cell culture infective dose $\left(\right.$ CCID $\left._{50}\right)$ as described in Box 2 ! CAUTION All experiments using the virus should be performed in an appropriate safety laboratory (L3) by trained and skilled personnel, taking the required security precautions, especially as virus stocks with high titer are to be used in these experiments.

- Stock solutions of test compounds (see REAGENT SETUP)

- Triton X-100 (5\% (vol/vol); Sigma, cat. no. T8787). It is used to inactivate the virus.

- HIV-1 p24 Core Profile ELISA kit (PerkinElmer, cat. no. NEK050B001KT)

\section{EQUIPMENT}

- Centrifuge (Multifuge 3S-R, Heraeus)

- Centrifuge tubes (50 ml; TPP, cat. no. 91050)

- Eppendorf high-performance microcentrifuge 5417R (Eppendorf, cat. no. 5407000.317 and cat. no. 5490061.004 (FA-45-24-11 fixed-angle rotor $24 \times 1.5 / 2.0 \mathrm{ml}$, including aerosol-tight, aluminum lid))

- Cup Eppendorf 1.5-ml safe lock (Eppendorf, cat. no. E10210)

- Tissue culture test plates 96F (TPP, cat. no. 92696)

- Polystyrene round-bottom tube ( 5 ml; BD Falcon, cat. no. 352054)

- Microscope

- $\mathrm{CO}_{2}$ incubator

- Laminar Airflow class IIA (Clean Air, cat. no. EF/A6)

- L3 safety laboratory

\section{REAGENT SETUP}

Complete medium RPMI-1640 containing 20 mM HEPES buffer supplemented with $10 \%$ (vol/vol) heat-inactivated FCS,

$2 \mathrm{mM}$ L-glutamine and $20 \mu \mathrm{g} \mathrm{ml}^{-1}$ gentamicin. This can be stored at $4{ }^{\circ} \mathrm{C}$ for 1 month. 


\section{BOX 2 | DETERMINATION OF THE 50\% CELL CULTURE INFECTIVE DOSE (CCID ${ }_{50}$ ) FROM A VIRUS STOCK}

The overview given below is based on a detailed protocol described in reference 1.

1. Fill a 96 -well microtiter plate with $100 \mu \mathrm{l}$ of complete medium.

2. Add $25 \mu \mathrm{l}$ of virus stock to six wells (wells $2 \mathrm{~B}$ to $2 \mathrm{G}$ ) of the microtiter plate.

3. Prepare nine serial, fivefold dilutions of the solutions in wells $2 \mathrm{~B}$ to $2 \mathrm{G}$ by transferring $25 \mu \mathrm{l}$ to the corresponding well in column 3 (wells $3 \mathrm{~B}$ to $3 \mathrm{G}$ ). Mix, change tips and repeat to transfer solution from column 3 to column 4, and similarly for each column up to column 10. Discard $25 \mu \mathrm{l}$ from column 10 so that in every well the volume is $100 \mu \mathrm{l}$. Do not add virus to column 11 , as this will be used as uninfected control.

4. Dispense $100 \mu \mathrm{l}$ of a $3 \times 10^{5}$ cells per $\mathrm{ml} \mathrm{MT-4}$ cell suspension into the microplate wells (wells $2 \mathrm{~B}$ to $11 \mathrm{G}$ ) and incubate the plate in a humidified atmosphere at $37{ }^{\circ} \mathrm{C}$ and $5 \% \mathrm{CO}_{2}$ in air for $5 \mathrm{~d}$.

5. After 5-d incubation, examine the cells microscopically for HIV-induced cytopathogenic effect. A well is scored positive if any trace of cytopathogenic effect is observed, as compared with the uninfected control. The CCID $_{50}$ is calculated using the Reed and Muench method ${ }^{43}$ as follows: $M=$ inv $\log \left\{x_{1}+\left[\left(x_{2}-x_{1}\right)\left(\left(y_{1}-50\right) / y_{1}-y_{2}\right)\right]\right\}$. In this equation, $y_{1}$ is the percentage of wells scored positive closest to but higher than $50 \%$ at a certain virus dilution; $y_{2}$ is the percentage of wells scored positive closest to but lower than $50 \%$ at a certain virus dilution; $x_{1}$ is the log from the dilution of the virus in which $y_{1}$ was observed; $x_{2}$ is the log from the dilution of the virus in which $y_{2}$ was observed; and $M$ is the dilution of virus stock that results in $1 \mathrm{CCID}_{50}$.

The amount of virus required for a time-of-addition experiment is expressed as multiplicity of infection, which refers to the number of infectious virus particles (or plaque-forming units, PFUs) per cell during infection. If 50 infectious particles (50 PFUs) are added to 100 cells, the multiplicity of infection is 0.5 . The CCID $_{50}$ is defined as the virus dose that is able to infect $50 \%$ of the cell cultures.

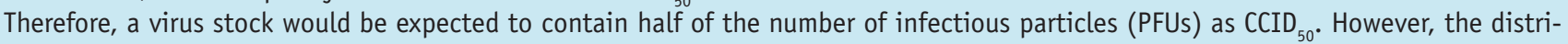
bution of virus in an infection occurs by a Poisson distribution. Therefore, a better estimate to convert CCID $_{50}$ to PFU is by multiplying the $\mathrm{CCID}_{50}$ by 0.7 to predict the PFU: $1 \mathrm{CCID}_{50}$ equals $0.7 \mathrm{PFU}$ or $1.43 \mathrm{CCID}_{50}$ is $1 \mathrm{PFU}$.

Preparation of stock solutions of test compounds Homogeneous aliquots of the test compounds have to be prepared. These can be prepared as described earlier in reference 1 . The most commonly used solvents are DMSO, water or buffer solutions. Ensure that the compounds dissolve well in the solvent used. As a rule of thumb, for long-term storage the compounds are stored at $4{ }^{\circ} \mathrm{C}$; however, the storage conditions and the maximum storage duration depend on the compound concerned. If one presumes degradation of a compound, we advise comparing the antiviral activity of a fresh solution with that of an old solution in the antiviral MT-4/MTT assay ${ }^{1}$. During the experiment, the compound solutions need to be maintained at room temperature $\left(21^{\circ} \mathrm{C}\right)$, protected from light.

\section{PROCEDURE}

\section{Sample preparation $\bigcirc$ TIMING 35 min}

1| Prepare a solution of the test compounds at, preferentially, 1,000 -fold their $\mathrm{IC}_{50}$ in complete medium. In the experiment, the final concentration of the compound will be 100-fold its $\mathrm{IC}_{50}$. Per assessed time point, $22 \mu \mathrm{l}$ (one well of a 96-well plate) is needed for each compound. The calculation for the required reagents of a typical experiment testing seven compounds at 11 time points is described in Box 3.

2| Transfer $22 \mu \mathrm{l}$ of each compound solution prepared in Step 1 to a $1.5-\mathrm{ml}$ tube; this will serve as time point $0 \mathrm{~h}$.

3| Cultivate MT-4 cells in a humidified atmosphere ( $\geq 95 \%$ humidity) at $37{ }^{\circ} \mathrm{C}$ and $5 \% \mathrm{CO}_{2}$. Subcultivate the cells every $2 \mathrm{~d}$ (seed at $3 \times 10^{5}$ ) or $3 \mathrm{~d}$ (seed at $1.5 \times 10^{5}$ cells per ml). Count the cells $\left(10 \times 10^{4}\right.$ cells are needed per 96 -well plate).

$\triangle$ CRITICAL STEP Choice of cell type is very important; a highly susceptible cell line is prerequisite for the success of the experiment.

4| Obtain the required number of cells for the experiment, pellet the cell suspension by centrifugation ( 5 min, $220 \mathrm{~g}$ at room temperature) and discard the supernatant. Resuspend the cells in complete medium at a density of $5 \times 10^{5}$ cells per $\mathrm{ml}$.

\section{Infection TIMING $45 \mathrm{~min}$, plus $1 \mathrm{~h}$ incubation time}

5| To this cell suspension, add the required amount of virus to reach a multiplicity of infection of 0.5 or $7.2 \times 10^{4}$ CCID $_{50}$ per well; this is bulk infection (See Box 2 for virus titration and Box $\mathbf{3}$ for example calculations).

! CAUTION All experiments using virus should be performed in an appropriate safety laboratory (L3) by trained and skilled personnel, taking the required security precautions, especially as virus stocks with high titer are to be used in these experiments. 


\section{BOX 3 | EXAMPLE OF A CALCULATION FOR THE REQUIRED REAGENTS FOR A TIME-OF-ADDITION EXPERIMENT}

This example describes the calculations of the amount of reagents required for 7 drugs +1 no-drug control and 11 time points $(0,1,2$,

$3,4,5,6,7,8,24$ and $25 \mathrm{~h}$ ).

1. Dextran sulfate $\left(100 \mu \mathrm{g} \mathrm{ml}^{-1}\right.$ final concentration)

2. AZT $\left(0.5 \mu \mathrm{g} \mathrm{mL}^{-1}\right.$ final concentration)

3. Ritonavir ( $2 \mu \mathrm{g} \mathrm{ml}^{-1}$ final concentration)

4. 'Unknown' compound (100-fold its IC ${ }_{50}$ )

5. 'Unknown' compound (100-fold its $\mathrm{IC}_{50}$ )

6. 'Unknown' compound (100-fold its $\mathrm{IC}_{50}$ )

7. 'Unknown' compound (100-fold its $\left.\mathrm{IC}_{50}\right)$

8. No-drug control

\section{Compound dilution}

Prepare a tenfold concentrated solution of compound in complete medium. For every time point (well) $22 \mu \mathrm{l}$ is needed. For time point $0 \mathrm{~h}$, you need to add the compound twice as the solution is washed out $1 \mathrm{~h}$ after infection; therefore, for 12 times, $22 \mu \mathrm{l}$ of solution is needed. You need a total of $12 \times 22 \mu \mathrm{l}=264 \mu \mathrm{l}$ of a $10 \times$ compound solution (e.g., for dextran sulfate DS5000, you need $264 \mu \mathrm{l}$ at $1,000 \mu \mathrm{gl}^{-1}$ ). Usually, we prepare more compound solution (in this case, $300 \mu \mathrm{l}$ ) than exactly required, as some volume is lost because of repetitive pipetting.

Cells

A total of $10 \times 10^{4}$ cells are needed per 96 well. For 7 compounds +1 no-compound control and 11 time points, $8 \times 11=88$ wells are needed, this yields a total of $88 \times 10 \times 10^{4}=8.8 \times 10^{6}$ cells.

Virus

A multiplicity of infection (MOI) of 0.5 is required, meaning that one in two cells should be infected. Thus, for $10 \times 10^{4}$ cells, the addition of virus at $7.2 \times 10^{4} \mathrm{CCID}_{50}$ is needed (see Box 2). The $\mathrm{CCID}_{50}$ of a virus stock is determined by titration and by using the Reed and Muench method ${ }^{43}$. For a protocol on how to titrate virus, see Box 2 and reference 1. For example, if the $\mathrm{CCID}_{50}$ of the virus stock is $8 \times 10^{5}$, an 11 -fold dilution of the stock is needed to reach a CCID $_{50}$ of $7.2 \times 10^{4}$ in the experiment.

Thus, the final volume in the wells is $222 \mu \mathrm{l}$ (200 $\mu \mathrm{l}$ cells and virus $+22 \mu \mathrm{l}$ compound suspension) and there are 88 wells for an experiment with 7 compounds +1 no-compound control and 11 time points, yielding a total volume of $19,536 \mu$ l. Virus stock dilution is 11 -fold as calculated above; this means $1,776 \mu \mathrm{l}(19,536 \times 1 / 11)$ of virus stock is necessary. The required number of cells, $8.8 \times 10^{6}$ cells, are pelleted by centrifugation, the supernatant is removed by decanting and the cells are resuspended in $17,600 \mu \mathrm{l}$ ( 88 wells $\times$ $200 \mu \mathrm{l})-1,776 \mu \mathrm{l}$ (the volume of virus suspension) $=15,824 \mu \mathrm{l}$ of complete medium. Then, the cells are infected by adding $1,776 \mu \mathrm{l}$ of virus stock (mix very well), and $200 \mu \mathrm{l}$ of the cell suspension is immediately dispensed into the $1.5-\mathrm{ml}$ tubes containing $22 \mu \mathrm{l}$ of compound yielding the $0 \mathrm{~h}$ sample; continue the protocol at Step 6 of the main PROCEDURE. Note: Usually we prepare more reagents than exactly required, as some volume is lost because of repetitive pipetting.

6| Immediately after infection, add $200 \mu \mathrm{l}$ of this suspension (bulk infection) to the 1.5 -ml tubes containing $22 \mu \mathrm{l}$ of each compound solution at 1,000-fold its $\mathrm{IC}_{50}$; these are the tubes from Step 2, which represent time point 0.

7| Place the $1.5-\mathrm{ml}$ tubes and the rest of the bulk infection at $37{ }^{\circ} \mathrm{C}$ in a humidified atmosphere of $5 \% \mathrm{CO}_{2}$ in air. Incubate for $1 \mathrm{~h}$.

8| After $1 \mathrm{~h}$ of incubation, add $1 \mathrm{ml}$ of complete medium to each $1.5-\mathrm{ml}$ tube and enlarge the volume of the bulk suspension to $40 \mathrm{ml}$ with complete medium.

9| Pellet the infected cells in the 1.5 - $\mathrm{ml}$ tubes and in the bulk infection by centrifugation ( $4 \mathrm{~min}, 330 \mathrm{~g}$, room temperature). Remove the supernatants and resuspend the cells in $40 \mathrm{ml}$ of complete medium.

10| Repeat Step 9 twice (a total of three centrifugations), and finally resuspend in complete medium (200 $\mu \mathrm{l}$ for the 1.5 - $\mathrm{ml}$ tubes and $5 \times 10^{5}$ cells per $\mathrm{ml}$ for the bulk infection).

$\triangle$ CRITICAL STEP Appropriate washing to remove the unbound virus is necessary to minimize background.

11| During the washing steps (Steps 9 and 10), add $22 \mu$ l of each compound solution in the wells of the 96-well plate, which will be used for time points 0 and $1 \mathrm{~h}$.

12| Transfer $200 \mu \mathrm{l}$ from the bulk suspension to all wells of time point $1 \mathrm{~h}$ and transfer $200 \mu \mathrm{l}$ from the 1.5 -ml tubes to the $22 \mu \mathrm{l}$ of compound solution in the plate corresponding to time point 0 . 
Figure 3 | Schematic illustration of the HIV replication cycle and a typical result from a time-of-addition experiment. (a) Chronological representation of the essential steps in the HIV-1 viral replication cycle. (b) Example of typical results obtained with the well-characterized anti-HIV drugs: dextran sulfate (an inhibitor of the viral adsorption to the host cell) ${ }^{35}$, AMD3100 (targeting the CXCR4 coreceptor binding) ${ }^{36}$, NV038 (an NCp7 inhibitor) ${ }^{37}$, AZT (an NRTI) ${ }^{38,}$ nevirapine (an NNRTI) ${ }^{39}, \mathrm{~L}-708,906$ (a strand transfer integrase inhibitor $)^{40}$, WP7-5 (a transcription inhibitor) ${ }^{24,41}$ and ritonavir (a protease inhibitor) ${ }^{42}$. Viral replication is inhibited up to a time point corresponding to the occurrence of the replication process targeted by the drug.

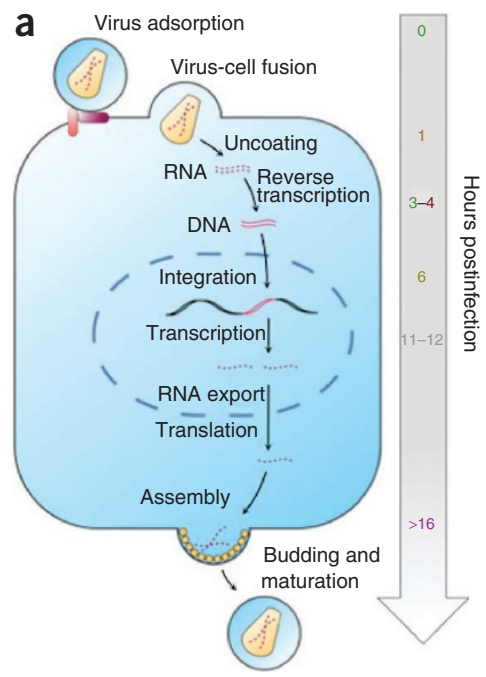

13| Mix the bulk suspension again and add $200 \mu \mathrm{l}$ to each remaining well in the 96 -well plate that will be used for the experiment. Place the plate at $37{ }^{\circ} \mathrm{C}$ in a humidified atmosphere of $5 \% \mathrm{CO}_{2}$ in air, and store the compound solutions in the dark at room temperature.

\section{Compound addition $\bigcirc$ TIMING 5 min for each time point, with intervals of $1 \mathrm{~h}$}

14| Each hour, add $22 \mu \mathrm{l}$ of the compound dilution to the wells corresponding to the correct time point and place the plate back at $37{ }^{\circ} \mathrm{C}$ in a humidified atmosphere of $5 \% \mathrm{CO}_{2}$ in air.

15 At $31 \mathrm{~h}$ after infection, microscopically score the plate for cytotoxicity by visually monitoring the cell morphology and/or for eventual crystallization/precipitation of the compounds in solution. Next, take $110 \mu$ supernatant from each well, inactivate by adding $12 \mu \mathrm{l}$ Triton X-100 (5\%) and store at $-80{ }^{\circ} \mathrm{C}$ until you can quantify the virus-associated p24 core antigen by ELISA.

PAUSE POINT The samples may be stored at $-80^{\circ} \mathrm{C}$ (for up to 6 months) without affecting the results.

16| Quantify the virus-associated p24 core antigen in the supernatant by ELISA; we use a commercially available kit from PerkinElmer and follow the manufacturer's instructions.

17| Plot the amount of p24 (pg ml-1) versus time points (see Fig. 3, panel b).

? TROUBLESHOOTING

? TROUBLESHOOTING

Troubleshooting advice can be found in Table 1.

TABLE 1 | Troubleshooting table.

\begin{tabular}{|c|c|c|}
\hline \multirow[t]{2}{*}{$\begin{array}{l}\text { No complete block of replication } \\
\text { is observed }\end{array}$} & $\begin{array}{l}\text { Concentration of compound used is } \\
\text { too low }\end{array}$ & $\begin{array}{l}\text { Increase compound concentration; cytotoxicity and solubility } \\
\text { of the compound in aqueous medium will be the limiting } \\
\text { factors }\end{array}$ \\
\hline & $\begin{array}{l}\text { Compound is unable to induce a } \\
\text { complete block of viral replication }\end{array}$ & $\begin{array}{l}\text { If the nonzero residual activity is consistently lower than the } \\
\text { 'no compound' control, it can be assumed that these time } \\
\text { points occur before the target of action }\end{array}$ \\
\hline $\begin{array}{l}\text { Starting from } 0 \mathrm{~h} \text {, a slight slope } \\
\text { in loss of activity with no clear } \\
\text { jump is observed }\end{array}$ & Toxicity of the compound & Reduce compound concentration \\
\hline
\end{tabular}


TIMING

Sample preparation

Steps 1-4: $35 \mathrm{~min}$

Infection

Steps 5 and 6: $10 \mathrm{~min}$

Step 7: 1-h incubation

Steps 8-12: $30 \mathrm{~min}$

Step 13: 5 min

Compound addition

Step 14: 5 min for each compound, with intervals of $1 \mathrm{~h}$

Step 15: $20 \mathrm{~min}$

Step 16: Time required to perform p24 ELISA is dependent on the kit and corresponding manufacturer's instructions

Step 17: $10 \mathrm{~min}$

Time from start of experiment until obtaining the final results: $\sim 2 \mathrm{~d}$

\section{ANTICIPATED RESULTS}

This protocol enables the target of action of newly discovered antiviral drugs to be determined in cell culture. For example, the RT inhibitor AZT is able to inhibit the replication of HIV-1 when it is present within the first $3 \mathrm{~h}$ of infection (Fig. $3 \mathbf{b}$ ); on the contrary, when it is added at $4 \mathrm{~h}$ after infection or later, it is unable to inhibit the viral replication because its target of action (the reverse transcription process) has already occurred and the target is no longer of importance for the further replication of the virus in a single round of infection. It should be pointed out that it is imperative to include control drugs with a known and well-characterized target of action in each experiment. When a drug with an unknown target of action shows a similar profile to the established anti-HIV agent, it strongly suggests that this drug targets the same process or at least targets one that is operative at the same time. Most notably, using this assay makes it possible to discriminate between an RT inhibitor of the nucleoside RT inhibitor type (NRTI) versus NNRTI type (Fig. 3). Indeed, we have consistently observed in all experiments that NRTIs ( $2^{\prime}, 3^{\prime}$-dideoxynucleoside (ddN) analogs) lose their antiviral activity exactly $1 \mathrm{~h}$ before that of any NNRTI. This is most likely because of the fact that ddN analogs need to undergo phosphorylation by cellular enzymes before becoming active, as chain terminators, in the RT reaction.

One should keep in mind that for drugs with a dual target of action, i.e., one molecule targeting two distinct steps within the replication cycle, always the last occurring target in the viral replication will be revealed by this experiment, as this is the last step at which replication can be blocked by the inhibitor. To illustrate this point, several combinations of two wellknown HIV inhibitors were combined in one experiment (Fig. 4). In the case of dextran sulfate (an inhibitor of viral entry) combined with AZT (an RT inhibitor), the TOA assay only reveals reverse transcription as a target for this combination. For AZT combined with L-870,810 (an integrase inhibitor), only the integrase is revealed as a target. A special example of drugs with a dual mechanism of action are polysulfonate dendrimers, which at low concentrations in cell culture inhibit the viral adsorption but when added at higher concentrations also target a process coinciding with the viral reverse transcription (Fig. 5) ${ }^{34}$. This can be explained by both the extent of cellular uptake of the drug(s) at different concentrations and their differential potency against different processes. Therefore, in a TOA experiment, it is advised to test compounds at different concentrations.

It is possible that a compound will not completely block HIV replication. In many cases this is because of the compound being present at too low a concentration to completely inhibit the virus replication or having too low an intrinsic potency. In the first case, this can be remedied by increasing the concentration of the compound, but cytotoxicity and solubility in aqueous medium of the compound will be limiting factors. We have noticed that there are compounds that are able to inhibit the viral replication and generate an $\mathrm{IC}_{50}$ value in the replication assay but that do not reach a complete $(100 \%)$ block of viral replication because of a lack of intrinsic potency. Even when no

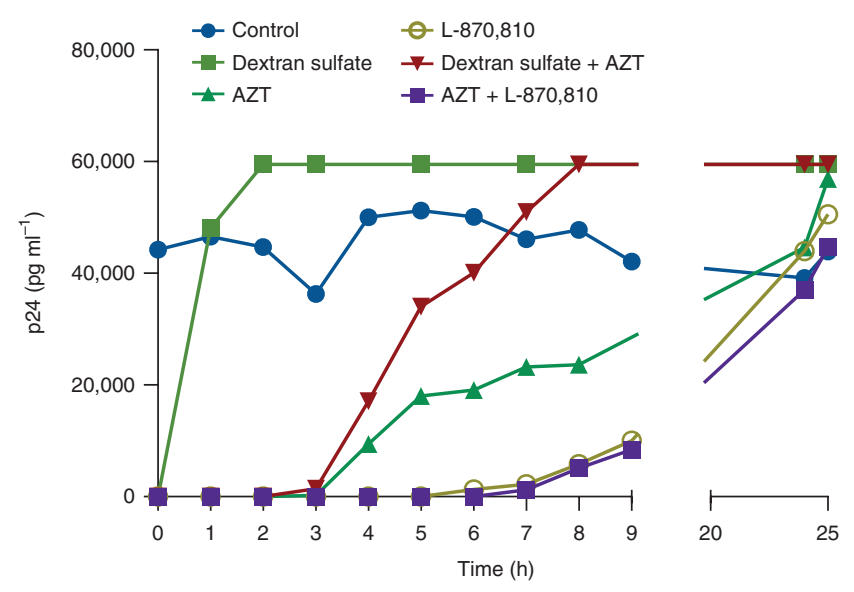

Figure 4 | A time-of-addition experiment reveals the last occurring target in the viral replication cycle. In this experiment, two well-known HIV inhibitors were combined. When a virus-binding inhibitor (dextran sulfate) is combined with a reverse transcriptase inhibitor (AZT), only the reverse transcription is revealed as the target, as the reverse transcription occurs later in time than the virus-binding process. Similarly, when a reverse transcriptase inhibitor (AZT) is combined with an integrase inhibitor $(L-870,810)$, only the integration is revealed as the target for this drug combination. 
complete inhibition of viral replication can be established with a certain compound, a satisfactory and reliable result could be obtained in this TOA assay. In this case, one can expect to see a residual amount of p24 at time points occurring before the target of the compound that is not zero (only reached when there is a $100 \%$ block of viral replication) but lower than in the control without the compound. It is also possible that sometimes a slight slope in loss of activity will be observed instead of a clear jump. This can be because of toxicity of the compound or because the compound is targeting a step in the viral replication that involves an iterative process that takes place for several hours.

Many variations of the TOA experiment can be envisaged, e.g., a so-called negative TOA experiment can be performed for drugs that need time to be processed by the host cell to become active in the cells. In such an experiment, the compound is added at different time points before the virus infection takes place. A similar approach can be used when the mechanism of action of a compound is based on the down- or upregulation of a cellular co-factor involved in viral replication. In addition, shorter time periods between compound addition (15 or $30 \mathrm{~min}$ ) can be used instead of the 1-h interval.

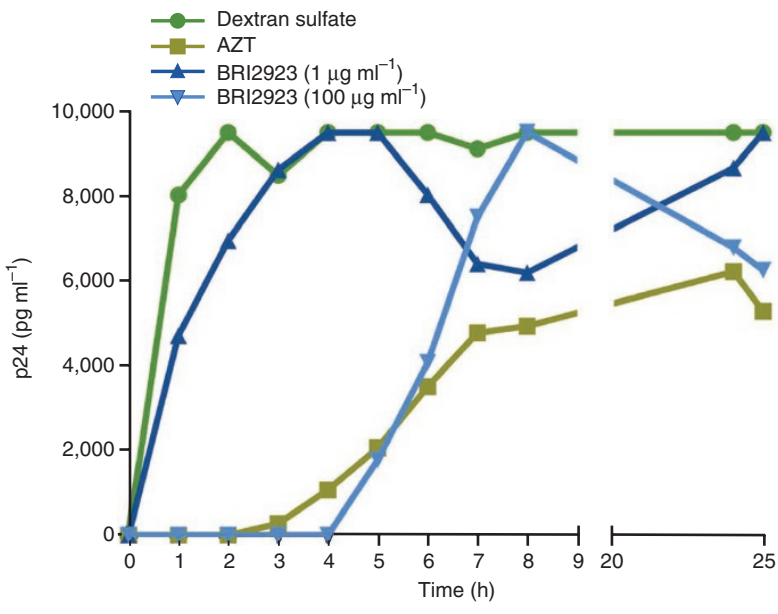

Figure 5 | Result obtained with a polyanionic dendrimer targeting two steps in the viral replication depending on the concentration tested. At low concentrations, the BRI2923 blocks virus entry, whereas at higher concentrations, it also targets the viral reverse transcription process. Dextran sulfate and AZT were included as reference compounds for virus entry and reverse transcription.
ACKNOWLEDGMENTS We thank K. Erven, C. Heens and L. Bral for fine technical and editorial assistance.

AUTHOR CONTRIBUTIONS R.P. and E.D.C. conceived the original protocol and D.D. and C.P. adjusted it to its current form and co-wrote the manuscript with E.D.C.

COMPETING FINANCIAL INTERESTS The authors declare no competing financial interests.

Published online at http://www.natureprotocols.com/.

Reprints and permissions information is available online at http://www.nature. com/reprints/index.html.

1. Pannecouque, C., Daelemans, D. \& De Clercq, E. Tetrazolium-based colorimetric assay for the detection of HIV replication inhibitors: revisited 20 years later. Nat. Protoc. 3, 427-434 (2008).

2. Pauwels, R. et al. Rapid and automated tetrazolium-based colorimetric assay for the detection of anti-HIV compounds. J. Virol. Methods 20, 309-321 (1988).

3. De Clercq, E. Suramin: a potent inhibitor of the reverse transcriptase of RNA tumor viruses. Cancer Lett. 8, 9-22 (1979).

4. Furman, P.A. et al. Phosphorylation of $3^{\prime}$-azido-3'-deoxythymidine and selective interaction of the $5^{\prime}$-triphosphate with human immunodeficiency virus reverse transcriptase. Proc. Natl Acad. Sci. USA 83, 8333-8337 (1986).

5. Chandra, P., Vogel, A. \& Gerber, T. Inhibitors of retroviral DNA polymerase: their implication in the treatment of AIDS. Cancer Res. 45, 4677s-4684s (1985).

6. Balzarini, J. et al. 9-[(2RS)-3-fluoro-2-phosphonylmethoxypropyl] derivatives of purines: a class of highly selective antiretroviral agents in vitro and in vivo. Proc. Natl Acad. Sci. USA 88, 4961-4965 (1991).

7. Parniak, M.A., Min, K.L., Budihas, S.R., Le Grice, S.F. \& Beutler, J.A. A fluorescence-based high-throughput screening assay for inhibitors of human immunodeficiency virus-1 reverse transcriptase-associated ribonuclease $\mathrm{H}$ activity. Anal. Biochem. 322, 33-39 (2003).

8. Engelman, A. \& Craigie, R. Identification of conserved amino acid residues critical for human immunodeficiency virus type 1 integrase function in vitro. J. Virol. 66, 6361-6369 (1992).

9. Debyser, Z., Cherepanov, P., Pluymers, W. \& De Clercq, E. Assays for the evaluation of HIV-1 integrase inhibitors. Methods Mol. Biol. 160, 139-155 (2001).
10. Dreyer, G.B. et al. Inhibition of human immunodeficiency virus 1 protease in vitro: rational design of substrate analogue inhibitors. Proc. Natl Acad. Sci. USA 86, 9752-9756 (1989).

11. Vercruysse, T., Pardon, E., Vanstreels, E., Steyaert, J. \& Daelemans, D. An intrabody based on a llama single-domain antibody targeting the $\mathrm{N}$-terminal alpha-helical multimerization domain of HIV-1 rev prevents viral production. J. Biol. Chem. 285, 21768-21780 (2010).

12. Vercruysse, T. et al. Measuring cooperative Rev protein-protein interactions on Rev-responsive RNA by fluorescence resonance energy transfer. RNA Biol. 8, 316-324 (1984).

13. Mitsuya, H. et al. Suramin protection of T cells in vitro against infectivity and cytopathic effect of HTLV-III. Science 226, 172-174 (1984).

14. Broder, S. et al. Effects of suramin on HTLV-III/LAV infection presenting as Kaposi's sarcoma or AIDS-related complex: clinical pharmacology and suppression of virus replication in vivo. Lancet 2, 627-630 (1985).

15. De Clercq, E. Suramin in the treatment of AIDS: mechanism of action. Antiviral Res. 7, 1-10 (1987).

16. Yahi, N. et al. Suramin inhibits binding of the V3 region of HIV-1 envelope glycoprotein gp120 to galactosylceramide, the receptor for HIV-1 gp120 on human colon epithelial cells. J. Biol. Chem. 269, 24349-24353 (1994).

17. Hamy, F. et al. An inhibitor of the Tat/TAR RNA interaction that effectively suppresses HIV-1 replication. Proc. Natl Acad. Sci. USA 94, 3548-3553 (1997).

18. Daelemans, D. et al. A second target for the peptoid Tat/transactivation response element inhibitor CGP64222: inhibition of human immunodeficiency virus replication by blocking CXC-chemokine receptor 4-mediated virus entry. Mol. Pharmacol. 57, 116-124 (2000).

19. Pluymers, W. et al. Viral entry as the primary target for the anti-HIV activity of chicoric acid and its tetra-acetyl esters. Mol. Pharmacol. 58, 641-648 (2000).

20. Robinson, W.E. Jr. L-chicoric acid, an inhibitor of human immunodeficiency virus type 1 (HIV-1) integrase, improves on the in vitro anti-HIV-1 effect of Zidovudine plus a protease inhibitor (AG1350). Antiviral Res. 39, 101-111 (1998).

21. Daelemans, D., Lu, R., De Clercq, E. \& Engelman, A. Characterization of a replication-competent, integrase-defective human immunodeficiency virus (HIV)/simian virus 40 chimera as a powerful tool for the discovery and validation of HIV integrase inhibitors. J. Virol. 81, 4381-4385 (2007).

22. Getchell, J.P. et al. Continuous production of a cytopathic human T-lymphotropic virus in a permissive neoplastic T-cell line. J. Clin. Microbiol. 23, 737-742 (1986). 
23. Tabarrini, 0. et al. Studies of anti-HIV transcription inhibitor quinolones: identification of potent N1-vinyl derivatives. ChemMedChem 5 , 1880-1892 (2010).

24. Van Neck, T. et al. Inhibition of the CRM1-mediated nucleocytoplasmic transport by $\mathrm{N}$-azolylacrylates: structure-activity relationship and mechanism of action. Bioorg. Med. Chem. 16, 9487-9497 (2008).

25. Daelemans, D., Pannecouque, C., Pavlakis, G.N., Tabarrini, 0. \& De Clercq, E. A novel and efficient approach to discriminate between pre- and post-transcription HIV inhibitors. Mol. Pharmacol. 67, 1574-1580 (2005).

26. Mitsuya, H. et al. Dextran sulfate suppression of viruses in the HIV family: inhibition of virion binding to $\mathrm{CD}^{+}$cells. Science 240, 646-649 (1988).

27. Daelemans, D., De Clercq, E. \& Vandamme, A.M. A quantitative GFP-based bioassay for the detection of HIV-1 Tat transactivation inhibitors. J. Virol. Methods 96, 183-188 (2001).

28. Morikawa, Y. et al. Complete inhibition of human immunodeficiency virus Gag myristoylation is necessary for inhibition of particle budding. J. Biol. Chem. 271, 2868-2873 (1996).

29. Pauwels, R. et al. Potent and selective inhibition of HIV-1 replication in vitro by a novel series of TIBO derivatives. Nature 343, 470-474 (1990).

30. Frankel, A.D. \& Young, J.A. HIV-1: fifteen proteins and an RNA. Annu. Rev. Biochem. 67, 1-25 (1998).

31. Keyaerts, E., Vijgen, L., Maes, P., Neyts, J. \& Van Ranst, M. In vitro inhibition of severe acute respiratory syndrome coronavirus by chloroquine. Biochem. Biophys. Res. Commun. 323, 264-268 (2004).

32. Keyaerts, E. et al. Plant lectins are potent inhibitors of coronaviruses by interfering with two targets in the viral replication cycle. Antiviral Res. 75, 179-187 (2007).

33. Pasternak, A.0. et al. Highly sensitive methods based on seminested realtime reverse transcription-PCR for quantitation of human immunodeficiency virus type 1 unspliced and multiply spliced RNA and proviral DNA. J. Clin. Microbiol. 46, 2206-2211 (2008).

34. Witvrouw, M. et al. Polyanionic (i.e., polysulfonate) dendrimers can inhibit the replication of human immunodeficiency virus by interfering with both virus adsorption and later steps (reverse transcriptase/integrase) in the virus replicative cycle. Mol. Pharmacol. 58, 1100-1108 (2000).

35. Ito, M. et al. Inhibitory effect of dextran sulfate and heparin on the replication of human immunodeficiency virus (HIV) in vitro. Antiviral Res. 7, 361-367 (1987).

36. De Clercq, E. et al. Highly potent and selective inhibition of human immunodeficiency virus by the bicyclam derivative JM3100. Antimicrob. Agents Chemother. 38, 668-674 (1994).

37. Pannecouque, C. et al. Inhibition of HIV-1 replication by a bisthiadiazolbenzene-1,2-diamine that chelates zinc ions from retroviral nucleocapsid zinc fingers. Antimicrob. Agents Chemother. 54, 1461-1468 (2010).

38. Nakashima, H. et al. Inhibition of replication and cytopathic effect of human $\mathrm{T}$ cell lymphotropic virus type III/lymphadenopathy-associated virus by $3^{\prime}$-azido-3'-deoxythymidine in vitro. Antimicrob. Agents Chemother. 30, 933-937 (1986).

39. Merluzzi, V.J. et al. Inhibition of HIV-1 replication by a nonnucleoside reverse transcriptase inhibitor. Science 250, 1411-1413 (1990).

40. Hazuda, D.J. et al. A naphthyridine carboxamide provides evidence for discordant resistance between mechanistically identical inhibitors of HIV-1 integrase. Proc. Natl Acad. Sci. USA 101, 11233-11238 (2004).

41. Tabarrini, 0 . et al. Structure modifications of 6 -aminoquinolones with potent anti-HIV activity. J. Med. Chem. 47, 5567-5578 (2004).

42. Kempf, D.J. et al. ABT-538 is a potent inhibitor of human immunodeficiency virus protease and has high oral bioavailability in humans. Proc. Natl Acad. Sci. USA 92, 2484-2488 (1995).

43. Reed, L.J. \& Muench, H. A simple method for estimating fifty percent endpoints. Am. J. Hyg. 27, 493-497 (1938). 